\section{Testagem de critérios de avaliação de um vocabulário básico crî̃érios de}

\author{
Evaluation of a core \\ vocabulary's criteria test
}

Gabriela DUARTE FERREIRA (UFRGS) gdf.gabriela@gmail.com \section{(1)}

DUARTE FERREIRA, Gabriela. Testagem de critérios de avaliação de um vocabulário básico.

Entrepalavras, Fortaleza, v. 7, p. 160-174, jan./jun. 2017.

Resumo: Este trabalho apresenta e discute a pertinência de uma grade de avaliação de listas de vocabulário básico. Seu objetivo é testar a eficiência da proposta da avaliação de Bell (2013), que possui os seguintes critérios: superordenação, produtividade semântica, produtividade formal, colocabilidade, antonicidade, e a neutralidade afetiva, a cultural e a contextual. Os resultados obtidos permitiram constatar que os critérios não foram discriminantes no momento de estabelecer se uma palavra deveria pertencer ou não a uma lista de vocabulário básico da Língua Espanhola. Isso ocorreu devido ao fato de os critérios não possuírem uma fundamentação estatística. Dessa maneira, chegouse à conclusão de que é necessária a elaboração de uma grade de critérios que leve em consideração fatores estatísticos.

Palavras-chave: Ensino de língua estrangeira. Vocabulário básico. Critérios de avaliação. 
Abstract: This paper presents and discusses the relevance of an evaluation grid of core vocabulary lists. The objective is to test the efficiency of Bell's (2013) evaluation model, which contains the following topics: superordinateness, semantic productivity, formal productivity, collocability, antonymy, affective neutrality, cultural neutrality and contextual neutrality. We conclude that Bell's (2013) gride do not discriminate if a word belongs or not to a basic spanish vocabulary list, because the criterions don't have a statistical basis. It was possible to conclude that it is necessary to design a grid of criterions based on statistical factors.

Keywords: Foreign language teaching. Core vocabulary. Evaluation criteria.

\section{Considerações iniciais}

A listagem de um vocabulário básico do espanhol mostra-se um fator primordial na compilação de dicionários para aprendizes de ELE Porém, tais listas ainda requerem de uma avaliação, pois, como aponta López Morales (2014, p. 2), um dos problemas mais comuns dessas listas, por exemplo, é que algumas palavras bem conhecidas e usadas não aparecem. Trata-se de um tema de intersecção entre lexicologia, lexicografia, ensino e aprendizagem de língua estrangeira que deve ser tratado à luz da linguística de corpus².

O modelo de critérios proposto por Bell (2013), baseado, segundo o próprio autor, nas propostas de Stubbs e Carter, é um dos mais recentes que pode ser utilizado para a avaliação de um vocabulário básico. No entanto, tal modelo ainda necessita ser testado, já que foi concebido originalmente para a língua inglesa. Dessa maneira, o objetivo desse trabalho é a testagem dos critérios compilados por Bell (2013). Para tanto, tais critérios serão aplicados em uma amostra de palavras do espanhol com a finalidade de testar se são efetivamente discriminantes. Embora essa fonte seja uma lista destinada a aprendizes alemães iniciantes de língua espanhola, o que interessa aqui é a amostra das palavras presentes nessa lista.

\footnotetext{
${ }^{1}$ ELE: Espanhol como língua estrangeira.

${ }^{2}$ A lexicologia é uma das áreas envolvidas porque se trabalha nessa pesquisa com o léxico considerado básico de uma língua. A lexicografia é outra das áreas envolvidas porque a investigação também compreende a produção de dicionários com as listas de palavras básicas. O ensino e aprendizagem de língua estrangeira fornece o público ao qual se destinam tanto as listas de vocabulários como os dicionários produzidos através destas. A partir disso, trabalharemos com corpora que nos auxiliarão na obtenção de resultados.
} 
v. 7 (1) $160-174$ jan/jun 2017

\section{O que é um vocabulário básico e quais são os critérios possíveis para avaliá-lo}

A partir das definições de Richards; Schmidt (2013, s.v. basic vocabulary e core vocabulary), poder-se-ia dizer que um vocabulário básico é um conjunto de itens léxicos caracterizados por ser de uso comum, de alta frequência e aplicável ao ensino e aprendizagem de línguas estrangeiras. No entanto, para Bell (2013, p. 1), a frequência não pode ser estabelecida como o único fator para determinar um vocabulário básico, mas sim constitui uma consequência da aplicação de determinados critérios. Assim, Bell (2013) estabelece dez critérios que determinam um vocabulário básico e que servem como teste: 1. O primeiro critério é o da superordenação, que estabelece que itens de vocabulário básico são mais frequentemente superordenados do que hipônimos (ex. a palavra home seria mais básica, enquanto que bungalow seria um item secundário). 2. O segundo critério é o da produtividade semântica, que propõe que um vocabulário básico possui maior número de acepções, de significados, do que palavras de ordem secundária. 3. Consoante o terceiro critério, o de produtividade formal, as palavras de vocabulário básico são usadas mais produtivamente, para criação de compostos e derivados, do que palavras secundárias (ex. arm pode produzir muito mais compostos, derivados, do que a palavra secundária limb). 4. O quarto critério, o de poder de substituição, propõe que palavras de vocabulário básico podem substituir palavras de ordem secundária. No entanto, tal critério já é presente no primeiro, o de superordenação, e portanto foi incluído neste. 5. O quinto critério proposto por Bell (2013) é o da colocabilidade [collocability] e diz respeito ao fato de que itens de vocabulário básico formam mais colocações (tem mais combinações possíveis com outras palavras) do que itens não básicos (ex. yellow possibilita mais combinações do que blonde). 6. O sexto critério, o da antonímia, estabelece que itens de vocabulário básico são mais prováveis de possuírem antônimos. Os quatro últimos critérios pertencem à categoria de neutralidade³, dentro da qual o autor distingue quatro subcategorias. A neutralidade afetiva se refere a que palavras de vocabulário básico não possuem conotações afetivas. A neutralidade cultural específica que um vocabulário básico tende a ser

3 Neutralidade, de acordo com Bell (2013), refere-se ao conceito de que um "vocabulário básico é genérico e não específico por natureza, mas, no mínimo, quatro tipos de neutralidade podem ser especificadas" [Core Vocabulary is by its nature generic and nonspecific, but least four types of neutrality can be specified.]. 
menos marcado por associações culturais. A neutralidade contextual determina que uma palavra de vocabulário básico não faz parte de um contexto particular específico. Por suas semelhanças, os critérios de neutralidade contextual e neutralidade de registro foram considerados apenas um. A partir dessa sobreposição, a grade foi adaptada em oito critérios (quadro 2), que foram aplicados e, consequentemente, testados na avaliação de um vocabulário básico.

Quadro 1: Grade de avaliação compilada por Bell (2013)

\begin{tabular}{|c|c|}
\hline 1) Superordenação & $\begin{array}{l}\text { Itens de vocabulário básico são mais } \\
\text { frequentemente superordenados do que } \\
\text { hipônimos. }\end{array}$ \\
\hline 2) Produtividade Semântica & $\begin{array}{l}\text { O vocabulário básico possui mais significados } \\
\text { do que palavras de ordem secundária. }\end{array}$ \\
\hline 3) Produtividade formal & $\begin{array}{l}\text { Palavras de vocabulário básico são usadas } \\
\text { mais produtivamente para a criação de outras } \\
\text { palavras do que palavras secundárias. }\end{array}$ \\
\hline 4) Poder de substituição & $\begin{array}{l}\text { Itens de vocabulário básico podem substituir } \\
\text { palavras de ordem secundária. }\end{array}$ \\
\hline 5) Colocabillidade [collocability] & $\begin{array}{l}\text { Itens de vocabulário básico formam mais } \\
\text { colocações (têm mais combinações permitidas } \\
\text { com outras palavras) do que itens não básicos. }\end{array}$ \\
\hline 6) Antonicidade & $\begin{array}{l}\text { Itens de vocabulário básico são mais prováveis } \\
\text { de possuir antônimos do que itens de palavras } \\
\text { secundárias. }\end{array}$ \\
\hline 7) Neutralidade afetiva & $\begin{array}{l}\text { Palavras de vocabulário básico não possuem } \\
\text { conotações afetivas que se baseiam em atitudes } \\
\text { e sentimentos. }\end{array}$ \\
\hline 8) Neutralidade cultural & $\begin{array}{l}\text { Itens de vocabulário básico tendem a ser } \\
\text { menos marcados por associações culturais e } \\
\text { mais diretamente traduzíveis de uma língua a } \\
\text { outra. }\end{array}$ \\
\hline 9) Neutralidade contextual & $\begin{array}{l}\text { Itens de vocabulário básico não fazem parte de } \\
\text { um contexto particular. }\end{array}$ \\
\hline 10) Neutralidade de registro & $\begin{array}{l}\text { O vocabulário básico não é restringido a um } \\
\text { registro particular. }\end{array}$ \\
\hline
\end{tabular}

Fonte: Bell (2013, p. 1-2)

Quadro 2: Grade de avaliação adaptada

\begin{tabular}{|l|}
\hline \multicolumn{1}{|c|}{ Critérios } \\
\hline $\begin{array}{l}\text { 1) Superordenação } \\
\text { (A palavra é superordenada?) }\end{array}$ \\
\hline
\end{tabular}


v. 7 (1)

$160-174$

jan/jun

\section{7}

\begin{tabular}{|l|}
\hline $\begin{array}{l}\text { 2) Produtividade Semântica } \\
\text { (Número de acepções no DRAEe) }\end{array}$ \\
\hline $\begin{array}{l}\text { 3) Produtividade Formal } \\
\text { (Número de derivados, compostos) }\end{array}$ \\
\hline $\begin{array}{l}\text { 4) Colocabilidade [collocability] } \\
\text { (A palavra forma colocações ou não?) }\end{array}$ \\
\hline $\begin{array}{l}\text { 5) "Antonicidade" } \\
\text { (A palavra possui antônimo?) }\end{array}$ \\
\hline 6) Neutralidade Afetiva \\
\hline 7) Neutralidade Cultural \\
\hline $\begin{array}{l}\text { 8) Neutralidade Contextual } \\
\text { (A palavra é marcada diatecnicamente?) }\end{array}$ \\
\hline
\end{tabular}

\section{Repertório léxico para a aplicação da grade de critérios}

Embora, e segundo o exposto na Introdução, os repertórios léxicos sejam extremamente úteis, ainda constituem materiais de apoio pouco conhecidos para o ensino e aprendizagem de uma língua estrangeira. Para o caso específico da Língua Espanhola, essas obras não somente não são frequentes como também são de difícil aquisição4. Curiosamente, para o ensino de espanhol voltado para falantes do alemão, esses repertórios léxicos são muito mais frequentes ${ }^{5}$. Com o intuito de desenvolver pesquisas que permitam estabelecer qual é o vocabulário básico da Língua Espanhola, começou-se por avaliar o repertório léxico presente em Almedros de la Rosa; Schellert; Wirth (2014). Embora esse repertório tenha sido concebido como auxílio para o aprendiz alemão do espanhol, o que interessa para efeitos desse trabalho, como explicitado na Introdução, é a lista de vocábulos em Língua Espanhola. Esse repertório léxico apresenta uma proposta das mil palavras mais frequentes do espanhol [Die 1.000 Wichtigstem Wörter Spanisch] ordenadas em dezessete temas: família e amigos; descrever o mundo; tempo livre e hobbies; corpo e saúde; sentimentos e emoções; curtindo a boa mesa; moda e beleza; ir às compras; morar e viver; natureza e meio ambiente; tempo e espaço; escola e emprego; sociedade e política; os meios de comunicação e a informação; transporte, tráfego e viagens;

\footnotetext{
4 Acessando sites de livrarias de cobertura nacional como livraria Cultura e Saraiva, procurou-se por "vocabulário básico de espanhol". No entanto, tais livrarias não apresentaram nenhuma obra de referência para tal tema. Buscando em sites de livrarias de maior cobertura, como a Librería Casa del Libro, os resultados foram os mesmos. Não foi encontrada nenhuma obra de referência para o tema.
}

5 Como, por exemplo, Álvarez Olañeta; Bonachera Álvarez (2015) e Tschirner (2008). 
número e fatos; algo da gramática. Dentro de cada tema há subtemas como: eu me chamo, a minha família e boas maneiras.

Para a avaliação desse repertório, optou-se por estabelecer uma amostragem de palavras que fosse representativa das 1.176 contidas na obra. Utilizou-se o método de amostragem sistemática constante de ordem $\mathrm{K}$, que consiste em retirar $\mathrm{K}$ elementos de uma lista ordenada. Seguindo a progressão da listagem de vocábulos, considerou-se o primeiro vocábulo da lista e se desconsiderou o seguinte; o terceiro vocábulo se considerou e o quarto se desconsiderou novamente, e assim, sucessivamente até o esgotamento da listagem. Dessa maneira, o corpus foi reduzido à sua metade, a 588 palavras. Reaplicou-se o método, reduzindo a amostra, dessa vez, a 294 palavras. Se o método fosse aplicado novamente, haveria subtemas que não estariam representados por nenhuma palavra. Por essa razão, optou-se por estabelecer uma amostra que também fosse representativa dos 69 subtemas. A amostra de 294 palavras foi dividida pelos 69 subtemas, obtendo-se o resultado de 4,2 palavras por subtema. O valor de 4,2 foi dividido à sua metade, resultando em 2. Assim, da lista de 294 palavras, foram consideradas as duas primeiras de cada um dos 69 subtemas. Desse modo, foi obtida uma amostra de 126 palavras representativas das 1.176. Nessa amostra foram aplicados os critérios da grade de avaliação adaptada de Bell (2013).

\section{Análise dos dados}

O objetivo da aplicação da grade de critérios adaptada na amostragem de 126 palavras foi avaliar se o repertório léxico era representativo de fato de um vocabulário básico da Língua Espanhola. Segue a análise juntamente com os resultados obtidos na aplicação de cada um dos critérios:

Superordenação

Segundo Bell (2013), as palavras de vocabulário básico são mais frequentemente superordenadas do que hipônimos ${ }^{6}$. No entanto, o

\footnotetext{
6 "Hipônimo consiste em uma relação entre duas palavras, na qual o significado de uma das palavras inclui o significado de outra palavra. Por exemplo, (...) as palavras animal e cachorro são relacionadas de uma maneira que cachorro se refere a um tipo de animal, e animal é um termo geral que inclui cachorro e outros tipos de animais. Em termos específicos cachorro é chamado de hipônimo, e o termo geral, animal, é chamado superordenado" [a relationship between two words, in which the meaning
} 
v. 7 (1)

$160-174$

jan/jun

2017

166

critério não se aplica, pois é perceptível que não existem hipônimos transparentes para a maior parte das palavras da amostra, como é possível exemplificar na tabela abaixo em: agradecer, besar, comportarse, amable e pareja. Essas palavras não possuem hipônimos que as façam ser classificadas como palavras hiperônimas ou superordenadas. Contrariando o critério de Bell (2013), parte da amostra de 126 palavras analisadas apresenta hipônimos ao invés de superordenados, como por exemplo, el avión e la bicicleta, que pertencem ao superordenado vehículo/medio de transporte. Porém, a própria obra oferece uma relação hierárquica superordenada, pois classifica em conjuntos de temas e subtemas as suas mil palavras mais frequentes do espanhol. Assim, por exemplo, as palavras mamá, hermana/hermano e tío fazem parte do subtema "a minha família", que faz parte do tema "família e amigos". É necessário salientar que, ainda que essa relação superordenada faça parte da estruturação da obra, ela não corresponde ao critério proposto por Bell (2013).

Quadro 3: Exemplo de testagem do critério de Superordenação

\begin{tabular}{|l|l|l|l|l|l|}
\hline Critérios & agradecer & besar & comportarse & amable & pareja \\
\hline $\begin{array}{l}\text { 1) Superordenação } \\
\text { (a palavra é superordenada } \\
\text { ou não?) }\end{array}$ & $\begin{array}{l}\text { Não se } \\
\text { aplica }\end{array}$ & $\begin{array}{l}\text { Não se } \\
\text { aplica }\end{array}$ & Não se aplica & $\begin{array}{l}\text { Não se } \\
\text { aplica }\end{array}$ & $\begin{array}{l}\text { Não se } \\
\text { aplica }\end{array}$ \\
\hline
\end{tabular}

Contudo, ainda que a hiperonímia não possa ser utilizada como critério, ela não deve ser descartada. Os estudos recentes baseiam-se principalmente nas áreas de aplicação da hiperonímia como um recurso lexical de substituição de palavras em textos e nas associações com aprendizagem de léxico em língua estrangeira7. Estudos como Silva (2012) indicam, a partir da análise em corpora de diferentes línguas, que palavras superordenadas como animal são realmente mais frequentes que seus possíveis hipônimos cachorro, gato, pássaro e cavalo, semelhante ao exposto no critério de superordenação.

Entretanto, ainda que palavras superordenadas possam ser mais

of one of the words includes the meaning of the other word. For example, in English the words animal and $\operatorname{dog}$ are related in such a way that dog refers to a type of animal, and animal is a general term that includes dog and other types of animal. The specific term, dog, is called a hyponym, and the general term, animal, is called a superordinate.] (RICHARDS; SCHMIDT, 2010, s.v. hyponymy).

7 Nation $(2006$, p. 136, 361) inclui a superordenação como uma das associações feitas para se aprender o significado de uma palavra por aprendizes de língua estrangeira. 
frequentes em corpora, a frequência não é o único fator determinante no desenvolvimento de um vocabulário básico, como indicou Bell (2013). Reafirmando essa conclusão, Carter (2012, p. 52) destaca que o fato de que palavras superordenadas sejam mais frequentes não implica "(...) que todos os superordenados serão palavras básicas ou que superordenação em si mesma é tão fácil de especificar como se poderia inferir pelos cândidos mas limitados exemplos citados $(\ldots)^{8 \prime}$.

\section{Produtividade semântica}

De acordo com Bell (2013), itens de vocabulário básico possuem mais significados. Para a aplicação desse critério, buscou-se a quantidade de acepções de cada uma das 126 palavras da amostra no dicionário padrão da Língua Espanhola, o DRAEe (2016). No entanto, em um primeiro momento, o critério apresentou-se inconclusivo, pois não foi possível determinar matematicamente um valor de referência. De fato, em Bell (2013) tão pouco há especificação de quantas acepções seriam necessárias para determinar se uma palavra possui uma alta ou baixa produtividade semântica.

A partir do número de acepções no DRAEe para cada uma das 126 palavras (ver exemplo abaixo), buscou-se determinar um valor que pudesse ser representativo de quantas acepções seriam necessárias para estabelecer que uma palavra pertence a um vocabulário básico. Para isso, foram calculados os valores de média9 e desvio padrão ${ }^{10}$. O valor da média resultou em 6,8 enquanto o desvio padrão foi de 7,4. Um valor de desvio padrão maior que a média indica que a distância média dos valores é maior que a própria média aritmética. Assim, a alta variação nos valores dessa amostra aponta que os números estão muito dispersos, de modo que não é possível estabelecer um valor matematicamente preciso. Dessa maneira, chegou-se à conclusão de que o critério não é discriminador, pois não foi possível estipular um valor de produtividade semântica preciso, que determine se uma palavra possui uma alta ou baixa produtividade semântica e se é pertencente a um vocabulário básico.

8 "This is not to say, however, that all superordinates will be core words or that superordinateness itself is as easy to specify as is implied by the neat but limited examples cited above or in the literature on structural semantics" (CARTER, 2012, p. 52).

9 É o valor central de um conjunto. É calculada somando-se todos os valores e dividindo-se o resultado pela quantidade de elementos somados.

10 É a medida de variabilidade ou dispersão dos dados. Calcula-se extraindo a raiz quadrada da variância. 
Quadro 4: Exemplo de testagem do critério de Produtividade Semântica

\begin{tabular}{|l|l|l|l|l|l|l|}
\hline Critérios & nombre & edad & mamá & pareja & esperar & besar \\
\hline $\begin{array}{l}\text { 2) Produtividade } \\
\text { semântica } \\
\text { Número de acepções } \\
\text { do DRAEe) }\end{array}$ & 7 & 6 & 2 & 8 & 6 & 4 \\
\hline
\end{tabular}

Produtividade formal

O terceiro critério de Bell (2013) estabelece que as palavras de um vocabulário básico formam mais derivados ${ }^{11}$. Para a testagem desse critério, contabilizou-se no DUE (2011) o número de derivados de cada uma das palavras. No entanto, semelhante ao critério anterior, os valores obtidos são dispersivos, de maneira que não é possível estimar uma medida precisa de quantos derivados seriam necessários para determinar se uma palavra pertence a um vocabulário básico. Como é possível ver no quadro abaixo, há palavras com sete derivados como hermano, outras com nenhum, como edad e outras com quatro, como nombre. Assim, o critério não se demonstrou positivo em sua testagem, pois não é capaz de distinguir um vocábulo como pertencente a um repertório lexical básico.

Quadro 5: Exemplo de testagem do critério de Produtividade Formal

\begin{tabular}{|l|l|l|l|l|l|}
\hline \multicolumn{1}{|c|}{ Critérios } & hermano & edad & nombre & amor & hora \\
\hline $\begin{array}{l}\text { 2) Produtividade Formal } \\
\text { (Número de derivados, } \\
\text { compostos) }\end{array}$ & 7 & 0 & 4 & 15 & 11 \\
\hline
\end{tabular}

Colocabilidade [collocability]

A colocabilidade [collocability], de acordo com Bell (2013, p. 2), refere-se ao conceito de que "itens de vocabulário básico formam mais colocações (têm mais combinações permitidas com outras palavras) do que itens não básicos" [Core vocabulary items form more collocations - have more allowable combinations with other words - than noncore items]. No entanto, tal definição não é clara, pois aponta para padrões colocacionais12 enquanto que o exemplo dado (yellow como uma palavra

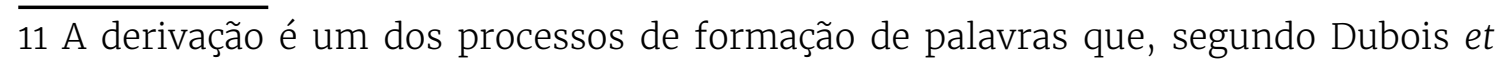
al (1973 apud CUNHA; CINTRA, 2013, p. 97) trata do "(...) conjunto de processos morfossintáticos que permitem a criação de unidades novas com base em morfemas lexicais (...)."

12 A partir de Johnson; Johnson (1999, s.v. collocation) e Richards; Schmidt (2013, s.v. collocation) podemos definir que padrão colocacional [collocation] é uma força 
que possibilita mais combinações que blonde) revela que o autor estava referindo-se a índices de combinação e não a padrões colocacionais. A proposta de índice de combinação léxica levou à investigação de padrões coligacionais13 que foram pesquisados através do Corpus de la Real Acedemia Española (CREA), somado ao corpus desenvolvido pelo professor Mark Davies, da Brigham Young University (BYUC), nos Estados Unidos. Do CREA, por exemplo, foram selecionadas dez frases de cada um dos 121 países e se chegou ao resultado em nombre de que, das 177 frases analisadas, 81 apresentavam nombre ocupando o padrão coligacional V+N. Através do segundo corpus, é possível reforçar esse padrão ao se perceber que, dentre as 5 palavras que mais combinam com nombre, três são verbos. (cuyo, recibe, lleva, vuestro, reciben).

Quadro 6: Exemplificação da testagem do critério de Colocabilidade

\begin{tabular}{|l|l|}
\hline \multicolumn{1}{|c|}{ Critérios } & \multicolumn{1}{c|}{ Nombre } \\
\hline 4) Colocabilidade & $\begin{array}{l}\text { - 81 casos em 177 frases apresentaram o } \\
\text { padrão coligacional V + N }\end{array}$ \\
(Formação de padrões coligacionais) & $\begin{array}{l}\text { - As cincos palavras que mais combinam } \\
\text { com nombre são: cuyo, recibe, lleva, vuestro, } \\
\text { reciben }\end{array}$ \\
\hline
\end{tabular}

Entretanto, o critério também não se mostrou discriminador na avaliação de um vocabulário básico. No entanto, não deixa de ser importante para outras áreas de estudo. Como aponta Carter (2012, p. $52)$,

(...) sem a teoria de colocação e testes associativos, fatores cruciais na determinação de efeitos estilísticos poderão ser também facilmente negligenciados e tais informações podem ser justamente tão importantes como base componente de informação semântica (...) (CARTER, 2012, p. 52) ${ }^{14}$.

vinculada na língua, organizando o léxico de forma que palavras ocorrem tipicamente juntas e demonstram certas redes de associações. Assim, são o modo no qual duas palavras são usadas juntas regularmente.

13 "A coligação significa os padrões gramaticais em que um item lexical aparece, ou sua frequente co-ocorrência com determinados itens gramaticais" (SHEPERD, 2009, p. 108. nota 8).

14 "However, without collocation theory and associated tests, crucial factors in the determination of stylistic effects can be too easily overlooked and such information may be just as important as basic componential semantic information, particularly in language learning contexts" (CARTER, 2012, p. 52). 
v. 7 (1)

$160-174$ jan/jun 2017

170

\section{Antonicidade}

Conforme Bell (2013), itens de vocabulário básico são mais prováveis de possuírem antônimos. Para a testagem desse critério, consultouse o DASA (1998). Entretanto, o critério, em um primeiro momento da investigação, resultou inconclusivo, pois, das 126 palavras da amostra, apenas 41 apresentaram antônimos de contrários simétricos, como alto e blando. A maioria da amostra possuía palavras como, por exemplo, amarillo, em que é inviável a construção de um antônimo simétrico.

A partir do avanço da pesquisa, formulou-se a hipótese de que o conceito de antonímia deveria ser ampliado, pois se entende que a antonímia não corresponde somente a pares opositivos de contraste simétrico.

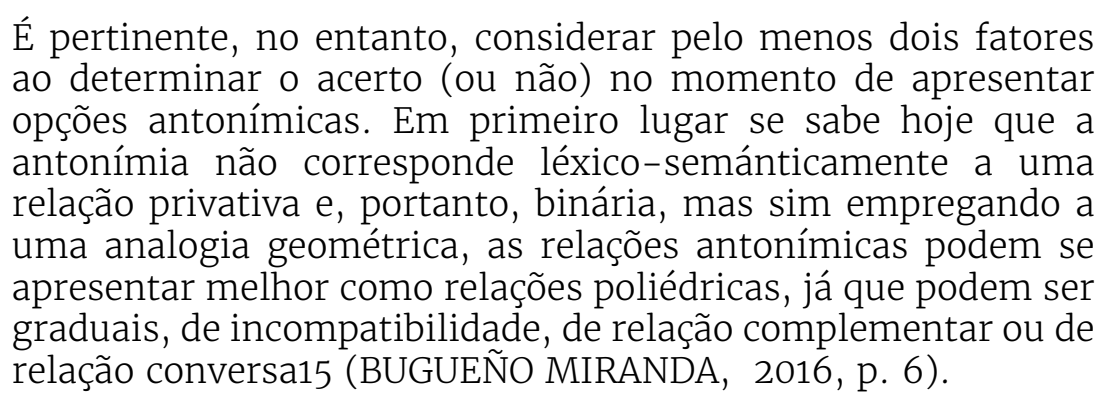

E pertinente, no entanto, considerar pelo menos dois fatores ao determinar o acerto (ou não) no momento de apresentar opções antonímicas. Em primeiro lugar se sabe hoje que a antonímia não corresponde léxico-semánticamente a uma relação privativa e, portanto, binária, mas sim empregando a uma analogia geométrica, as relações antonímicas podem se apresentar melhor como relações poliédricas, já que podem ser relação conversa15 (BUGUEÑO MIRANDA, 2016, p. 6)

Em vista disso, tomando por base Pérez; Pascual (2009, p. 117131), estabeleceram-se quatro tipos de antonímias para serem testadas na amostra de 126 palavras. Seriam estas a antonímia dicotômica, a gradual, a conversa e a poliédrica (ver quadro abaixo com definições e exemplos).

Quadro 7: Tipos de antonímia: definições e exemplos

\begin{tabular}{|l|l|}
\hline \multicolumn{1}{|c|}{ Tipo de antonímia } & \multicolumn{1}{c|}{ Definição } \\
\hline Antonímia dicotômica & Um membro exclui o outro. Ex.: vivo / muerto \\
\hline Antonímia gradual & $\begin{array}{l}\text { Os membros da oposição estão em uma relação } \\
\text { escalar. Ex.: frío / tibio / caliente }\end{array}$ \\
\hline Antonímia conversa & $\begin{array}{l}\text { Um membro constitui a negação do outro. Ex.: } \\
\text { comprar / vender. }\end{array}$ \\
\hline Antonímia poliédrica & $\begin{array}{l}\text { Há vários membros que estabelecem relações de } \\
\text { oposição entre eles. Ex.: os dias da semana. }\end{array}$ \\
\hline
\end{tabular}

Fonte: Pérez; Pascual (2009, p. 117-131)

15 "Es pertinente, sin embargo, considerar por lo menos dos factores que determinan el acierto (o no) en el momento de presentar opciones antonímicas. En primer lugar, se sabe hoy que la antonimia no corresponde léxico-semánticamente a una relación privativa $y$, por ende, binaria, sino que, empleando un símil geométrico, relaciones antonímicas se pueden representar mejor como relaciones poliédricas, ya que pueden ser graduales, de incompatibilidad, de relación complementaria o de relación conversa" (BUGUEÑO MIRANDA, 2016, p. 6). 
Assim, foram analisadas a presença ou ausência de cada tipo de antonímia na amostragem (ver quadro de exemplo abaixo). O resultado foi de que, do total de 126 palavras, 67 apresentaram algum tipo de antonímia, correspondendo a 53,2\% do total da amostra. Desse percentual de palavras que apresentaram algum tipo de antonímia, o mais frequente foi o de antonímia poliédrica, com 48,8\%; seguida da antonímia dicotômica, com 31,3\%; da antonímia gradual, com 13,8\%; e, em último, a antonímia conversa, com 6,3\%.

Quadro 8: Exemplificação da testagem do critério de "Antonicidade"

\begin{tabular}{|l|c|c|c|c|}
\hline & la afición & el invierno & el fútbol & participar \\
\hline Antonímia dicotómica & $\checkmark$ & $\mathrm{X}$ & $\mathrm{X}$ & $\mathrm{X}$ \\
\hline Antonímia gradual & $\mathrm{X}$ & $\checkmark$ & $\mathrm{X}$ & $\mathrm{X}$ \\
\hline Antonímia conversa & $\mathrm{X}$ & $\mathrm{X}$ & $\mathrm{X}$ & $\mathrm{X}$ \\
\hline Antonímia poliédrica & $\mathrm{X}$ & $\mathrm{X}$ & $\checkmark$ & $\mathrm{X}$ \\
\hline
\end{tabular}

Ainda que o critério tenha se mostrado expressivo em termos numéricos, pois um pouco mais da metade da amostra apresentou algum tipo de antonímia, a diferença não é estatisticamente significativa. Afinal, cerca de metade da amostra apresentou antonímia, enquanto a outra não. Dessa maneira, não é possível chegar a uma conclusão se esse critério discrimina se uma palavra deve pertencer ou não a um vocabulário básico. A antonicidade pode passar a ser um futuro candidato a critério discriminador, porém é necessário que seja somado a outros fatores, pois por si só não demonstrou diferença estatística significativa.

Neutralidade: Afetiva, Cultural e Contextual

Os três últimos critérios, neutralidade afetiva, cultural e contextual foram os únicos que se demonstraram coerentes e adequados na avaliação de um vocabulário básico. O primeiro (neutralidade afetiva) trata de que palavras básicas não possuem conotações afetivas. O segundo (neutralidade cultural) se refere a que itens de vocabulário básico tendem a ser menos marcados por associações culturais, como por exemplo, o uso de uma determinada palavra apenas em um país da língua. O terceiro (neutralidade contextual) trata de que palavras de vocabulário básico não estão marcadas tecnicamente, como por 
v. 7 (1)

$160-174$

jan/jun

2017

exemplo, o uso da palavra miocárdio ao invés de coração. Dessa maneira, também foram testados os três critérios de neutralidade nas 126 palavras da amostragem, averiguando a presença ou ausência de palavras com conotação afetiva, cultural ou contextual (ver quadro abaixo).

Quadro 8: Exemplificação da testagem dos critérios de Neutralidade Afetiva, Cultural e Contextual

\begin{tabular}{|l|c|c|c|c|c|}
\hline Critérios & nombre & edad & mamá & hermano & pareja \\
\hline 6) Neutralidade afetiva & $\checkmark$ & $\checkmark$ & X & $\checkmark$ & $\checkmark$ \\
\hline 7) Neutralidade cultural & $\checkmark$ & $\checkmark$ & $\checkmark$ & $\checkmark$ & $\checkmark$ \\
\hline 8) Neutralidade contextual & $\checkmark$ & $\checkmark$ & $\checkmark$ & $\checkmark$ & $\checkmark$ \\
\hline
\end{tabular}

De toda a amostra avaliada, apenas uma palavra dentre os três critérios não apresentou a neutralidade. Como pode ser visto no quadro acima, o vocábulo mamá foi o único que não possui a neutralidade afetiva, nesse caso, esperada para uma palavra de vocabulário básico. A partir desses fatores, pode-se concluir que os critérios de neutralidade afetiva, cultural e contextual formam parte de premissas básicas no momento de se construir uma lista de vocabulário destinada a aprendizes de língua estrangeira. Podemos confirmar essa premissa básica, ao percebermos que, na avaliação de materiais didáticos para ensino de língua estrangeira, um ponto chave é avaliar se o léxico presente possui a neutralidade cultural. Como aponta Benítez Pérez (1990, p. 325), “(...) os manuais publicados (...) devem ser reflexo do que conhecemos como nossa língua standard, aquela que nos serve para comunicarmos com todos os falantes do mundo hispânico" ${ }^{16}$

\section{Considerações finais}

As primeiras listas de vocabulário básico possuíam como parâmetro apenas a frequência das palavras dentro de um corpus. Segundo Bell (2013), a partir de estudos como os de Stubbs e Carter, que datam de 1986 e 1987, respectivamente, começou-se a somar outros fatores além da frequência. Porém, no que diz respeito a parâmetros para avaliar essas listas de vocabulário básico, percebe-se que, em trinta anos de investigação, ainda é pouco o que se sabe sobre como aferir essas listas. A pesquisa realizada constatou que a grade de Bell (2013)

16 (...) los manuales publicados (...) deben ser reflejo de lo que conocemos como nuestra lengua estándar, aquella que nos sirve para comunicarnos todos los hablantes del mundo hispánico" (BENÍTEZ PÉREZ, 1990, p. 325). 
não foi discriminante para avaliar um repertório léxico. Dentre outros fatores, foi possível averiguar que falta um fundamento estatístico para que uma análise quantitativa possa ser realizada. Assim, por exemplo, o critério segundo o qual palavras de vocabulário básico possuem mais superordenados do que hipônimos, pode parecer coerente. No entanto, no momento de se transformar isso em parâmetros avaliativos, os resultados numéricos não demonstraram significância.

Por fim, em atenção ao exposto no parágrafo anterior, percebese que é necessário reconsiderar a maneira como se deve elaborar uma grade de critérios que possua parâmetros estatísticos em sua composição.

\section{Referências}

ALMENDROS DE LA ROSA, María del Carmen; SCHLLERT, Eva; WIRTH, Christiane. Die 1.00o Wichtigsten Wörter. Stuttgart: Pons, 2014.

ÁLVAREZ OLAÑETA, Pedro; ÁLVAREZ BONACHERA Trinidad. Grundwortschatz Spanisch. 8000 Wörter zu über 100 Themen. Ismaning: Hueber, 2015.

BELL, Huw. Core Vocabulary. In: CHAPELLE, Carol (ed.). The Encyclopedia of Applied Linguistics. Hoboken: Blackwell Publishing Ltd., 2013.

BENÍTEZ PÉREZ, Pedro. Léxico real / Léxico irreal en los manuales de español para extranjeros. In: MONTESA PEYDRÓ, Salvador; GARRIDO MORAGA, Antonio (eds.). Actas Del Segundo Congreso Nacional de ASELE: Español para Extranjeros: Didáctica e Investigación, Madrid, del 3 al 5 de Diciembre de 1990. Asele, 1994. p. 325 - 333.

BUGUEÑO MIRANDA, F. V. Resenha a José Luis Durán, Sérgio Torres, Guillermo Blanco. Diccionario práctico de sinónimos, antónimos y parónimos. Logos. La Serena, v. 24/1, 2016, p. 286 - 290.

CARTER, Ronald. Vocabulary: Applied linguistic perspectives. London: Routledge, 2012.

CE. DAVIES, Mark. Corpus del Español: 100 million words, 1200s-1900s. Disponível em: http://www. corpusdelespanol. org, 2002; Acesso em: 19 de maio de 2016.

COCHRAN, William Gemmell. Amostragem sistemática. In: COCHRAN, William Gemmel. Técnicas de amostragem. Rio de Janeiro: Fundo de Cultura, 1965, p. $280-317$.

CREA. REAL. ACADEMIA ESPAÑOLA. Corpus de referencia del español actual. Disponível em: http://www.rae.es. Acesso em: 20 de jun. de 2016.

CUNHA, Celso; CINTRA, Lindley.Nova GramáticadoPortuguês Contemporâneo. Brasil: Lexicon, 2013.

DASA. PERDICES, José Manuel Blecua (Ed.). Diccionario avanzado de sinónimos y antónimos de la lengua española. Barcelona: Vox, 1998. 
v. 7 (1) $160-174$ jan/jun 2017

DRAEe. REAL ACADEMIA ESPAÑOLA. Diccionario de la Real Academia. Disponível em http://dle.rae.es/?w=diccionario, 2014. Acesso em: 27 de maio de 2016.

DUE. MOLINER, María. Diccionario de uso del español. Madrid: Gredos, 2001.

JOHNSON, Keith; JOHNSON, Helen. Encyclopedic Dictionary of applied Linguistics: A handbook for language teaching. Massachusetts: Blackwell Publishing, 1999.

LEYVA, Haydée Fernández. Posible aplicación del índice de disponibilidad léxica a la selección del vocabulario de manuales de ELE. MarcoELE: Revista de Didáctica Español Lengua Extranjera. s/l, v.20, p.1-13, 2015; Disponível $\mathrm{em}$ : http://marcoele.com/descargas/20/fernandez-disponiblidad_lexica. pdf; acesso em: 20 de maio de 2016.

LÓPEZ MORALES, Humberto. Lexical Availability Studies. In: JIMÉNEZ CATALÁN, Rosa María (ed.). Lexical Availability in English and Spanish Language as a Second Language, Education Linguistics. Heidelberg: Springer, 2014 .

MARTÍN, S.: La revisión del concepto de vocabulario en la gramática de E.L.E., MarcoELE: Revista de Didáctica Español Lengua Extranjera. s/l, v.9, p.157163, 2009. Disponível em: http://marcoele.com/descargas/expolingua_1999. martin.pdf; acesso em: 20 de maio de 2016.

NATION, Ian SP. Learning vocabulary in another language. Cambridge: CUP, 2006.

PÉREZ, Rafael García; PASCUAL, José Antônio. Relaciones de significado entre las palabras. In: MIGUEL, Elena de. (ed.) Panorama de la Lexicología. Barcelona: Ariel, 2009. p. 117-131.

RICHARDS, Jack C.; SCHMIDT, Richard W. Longman dictionary of language teaching and applied linguistics. London: Routledge, 2013.

SHEPHERD, T. Corpora de aprendiz de língua estrangeira: um estudo contrastivo de n-gramas. Veredas on-line - Linguistica de Corpus e Computacional, Juiz de Fora: UFJF, v. 2, p. 100-116, 2009.

SILVA, Mário André Coelho da. Hiperonímia e marcação. In: AMARAL, Eduardo Tadeu Roque (org.). Estudos de semântica. Belo Horizonte: FALE/UFMG, 2012, p.29-40.

TSCHIRNER, Erwin. Grund - und Aufbauwortschatz Spanisch nach Themen - Lernwörterbuch. Berlin: Cornelsen, 2008.

VIEIRA, Sonia. Análise de Variância. São Paulo: Atlas, 2006.

Recebido em: 23 de jan. de 2017.

Aceito em: 13 de jul. de 2017. 